\title{
Research on the Development of Guilin International Marathon Based on Information Platform and Its Countermeasures*
}

\author{
Yongfen Yang \\ Kunming University \\ Kunming, China 650500 \\ Liaokun Ye** \\ Kunming University \\ Kunming, China 650500 \\ **Corresponding Author
}

\author{
Feng Tian \\ Yunnan University \\ Kunming, China 650500 \\ Yunhai Chen \\ Kunming University \\ Kunming, China 650500
}

\begin{abstract}
With the increasing popularity of information technology, people have more and more demand for fitness. As a sports project integrating mass, fun and competitive, the marathon has developed rapidly in China in recent years. This paper studies the integration and development of Guilin International Marathon and Guilin's local climate, tourism and landforms through the literature review method and comparative analysis method, and finds out the problems in the development of Guilin International Marathon. Then the paper also proposes measures such as rational planning of the race route, setting special sub-projects, increasing the integration of the event and the venue, and using the information platform to carry out in-depth publicity and build the brand of the event, providing improvement suggestions for the future hosting of the Guilin International Marathon.
\end{abstract}

Keywords-Guilin International Marathon; information; tourism; status quo; countermeasures

\section{INTRODUCTION}

In 2016, China put forward the "Outline of the National Fitness Program", which clearly stated that it is necessary to vigorously develop the mass sports undertakings, and put the national fitness and the health of the whole people at the forefront of the development of sports. In recent years, due to the rising demand for mass training, the marathon in China has experienced explosive growth. The number, scale, quality and influence of the event are constantly improving. However, the promotion of sports in Guangxi is still in its infancy. Its network and information construction are still relatively fragmented, and the way for the masses to obtain sports information is relatively simple, which still causes some problems in the promotion of marathon in Guangxi.

*Fund: Kunming University 2018 undergraduate education and teaching reform project: Construction of information platform for college sports evaluation

\section{The CuRrent Situation OF THE DeVElopment OF THE GUILIN INTERNATIONAL MARATHON}

\section{A. Survey on the Number of Participatants}

The Guilin International Marathon has a certain improvement in the number of participants, number, level and source. In the just-concluded 2018 Guilin Marathon, the number of participants reached 25,000. The number of participants and the scale of the event are constantly expanding, and the number of entries is basically at the same level as the number of domestic double-standard events.

Among the geographical sources of the contestants, the participants in the Guangxi area are the main force of the event. In the first whole Malaysia, there were players from 15 countries and 31 provinces, municipalities and special administrative regions. Among them, foreign players are basically all from invited players. In the 2018 Guilin Marathon, 25,000 players from 30 countries and 31 provinces and municipalities across the country participated in the competition. Among them, there are more foreign friends and marathon enthusiasts in China, which is also a reflection of the expansion of Guilin Marathon.

\section{B. Investigation on the Route Design of the Event}

The 2016 Guilin Marathon event mainly passes through the Central Square, Binjiang Road, Jiefang East Road, Jiefang West Road, Xishan Road, Zhongyin Road, Jichang Road, Shanshui Avenue and Xicheng Avenue. The final destination is set in the "Grand Theatre, Library and Museum". From the official website of Guilin Marathon, it was found that in the 2017 marathon, the official website of the event gave a more detailed introduction to the route. The specific route of the half marathon and Happy 10k is also marked, and a color road map is attached to the article notice. However, the tourist attractions and related introductions of the route are not introduced in the information. 
In the introduction of the track in 2018, the information of the official website was gradually improved, and the specific ways of the three routes were introduced. Compared with the second session, there are also major adjustments. After the introduction of the road line, the famous spots and track views of the route were introduced in a larger space. These include national 5A tourist attractions, national 4A tourist attractions, urban landmarks, pathways to universities and historical and cultural attractions. This provides a more detailed introduction to the route and interpretation of the attraction. The contestants in other regions have a strategy for tourism, leisure and sightseeing.

\section{Investigation on the Organizations}

The organization of the event is basically similar to the structure of the marathon events in other cities in China. The sponsors of the event are the China Athletics Association, the People's Government of Guangxi Zhuang Autonomous Region and the People's Government of Guilin. The organizer is Guilin Municipal Affairs Bureau, Guilin Tourism Development Committee, Guilin Municipal Sports Bureau, Guilin Public Security Bureau, Guilin Communist Youth League Committee, etc. The organizer of the event is the Guilin City Conference Reception Management Office and Guangzhou Zhongti Sports Co., Ltd. The service volunteer team of the event is Guangzhou Zhongti Sports Co., Ltd. and Guilin College Volunteer Team.

\section{Investigation on the Funding Sources}

The source of funding for the Guilin International Marathon consists of government funding, title sponsorship, player registration fees, sponsor's advertising costs, and sponsor's in-kind sponsorship. The Guilin International Marathon has exceeded 20,000 people in the scale of the event. Except for some sponsors' promotional teams, the actual size of the event is about 15,000 . The total number of participants in the marathon is 6,500 , the registration fee is 160 yuan; the half-marathon registration fee is 120 yuan, the number of participants is 8,500; the number of Happy $10 \mathrm{~K}$ is 8,000 , the registration fee is 60 yuan, and the total registration fee is about 2.5 million. It is understood that Guilin Bank's title fee is 2 million. Other sponsors are mostly of the events and services, such as the track supply provided by Minggui Rice Noodles Company, and C'estbon provided drinking water and beverages. It can be seen that the source of funding for the Guilin International Marathon is much lower than that of Shanghai and Beijing. The lack of funds has led to restrictions on the use of more technology and technology, resulting in a decline in the overall quality of the event.

\section{E. Survey of the Application of Emerging Information Technology}

The marathon is a combination of mass and entertainment. In this case, the entire operation relies on the traditional way of operation can't meet the needs of the current event. The 2016 Guilin International Marathon event used emerging information technology in the registration and results announcement. This makes the work pressure of these two links smaller and more efficient. In 2017, relying on the information platform to establish a special propaganda organization in the propaganda process, its influence greatly exceeded that of 2016. The use of emerging self-media technology in 2018 has made the Guilin International Marathon unprecedentedly influential and has a certain reputation in China.

\section{PROBLEMS IN THE GUILIN INTERNATIONAL MARATHON}

\section{A. Insufficient Publicity}

The promotion of the event directly affects the popularity of the event. The popularity of the event affects the composition of the participants, the size of the event, the influence of the event and many other factors. Guilin International Marathon has a large gap in publicity compared to well-known marathons such as Beijing and Xiamen.

Guilin held two half-marathon races in 2011 and 2012 respectively. The first full marathon was held in 2016. The mid-term faults have reduced the influence of the Guilin Marathon, which makes the first two years of competition seem to be weak.

In addition, the Guilin International Marathon has a short operating cycle and a certain compression in the promotion time. This makes the event not enough time in the early stage of publicity, and the effect is not particularly satisfactory. In general, the promotion of large-scale events should be half a year or even longer, but the Guilin Marathon is only three months away, and the time is about doubled. The persistence and penetration effect of its propaganda is relatively poor.

\section{B. The Player's Performance Level Is Not High}

The Guilin Marathon is also less competitive in terms of performance than other Gold Label Road Races. The article compares the scores of contestants in the domestic competitions such as the Shanghai Marathon and the Xiamen Marathon, as shown in the table:

TABLE I. COMPARISON OF THE RESUltS OF MEN'S COMPETITIONS IN THE DOMESTIC COMPETITIONS SUCH AS THE 2017 SHANGHAi MARATHON AND THE XIAMEN MARATHON

\begin{tabular}{|l|l|l|l|l|l|}
\hline Ranking & $\begin{array}{l}\text { Guilin International } \\
\text { Marathon }\end{array}$ & $\begin{array}{l}\text { Beijing International } \\
\text { Marathon }\end{array}$ & $\begin{array}{l}\text { Shanghai International } \\
\text { Marathon }\end{array}$ & $\begin{array}{l}\text { Wuhan International } \\
\text { Marathon }\end{array}$ & $\begin{array}{l}\text { Lanzhou International } \\
\text { Marathon }\end{array}$ \\
\hline First place & $2: 22: 26$ & $2: 11: 18$ & $2: 08: 35$ & $2: 13: 51$ \\
\hline Second place & $2: 25: 48$ & $2: 11: 26$ & $2: 08: 36$ & $2: 14: 21$ \\
\hline Third place & $2: 27: 25$ & $*$ & $2: 09: 02$ & $2: 14: 42$ \\
\hline
\end{tabular}


TABLE II. COMPARISON OF THE RESUlts OF WOMEN'S COMPETITIONS IN THE DOMESTIC COMPETITIONS SUCH AS THE 2017 SHANGHAi MARATHON AND THE XIAMEN MARATHON

\begin{tabular}{|l|l|l|l|l|l|}
\hline Ranking & $\begin{array}{l}\text { Guilin } \\
\text { International } \\
\text { Marathon }\end{array}$ & $\begin{array}{l}\text { Beijing } \\
\text { International } \\
\text { Marathon }\end{array}$ & $\begin{array}{l}\text { Shanghai } \\
\text { International } \\
\text { Marathon }\end{array}$ & $\begin{array}{l}\text { Wuhan } \\
\text { International } \\
\text { Marathon }\end{array}$ & $\begin{array}{l}\text { Lanzhou } \\
\text { International } \\
\text { Marathon }\end{array}$ \\
\hline First place & $2: 45: 00$ & $2: 27: 44$ & $2: 22: 40$ & $2: 34: 50$ & $2: 32: 03$ \\
\hline Second place & $2: 55: 24$ & $2: 30: 44$ & $2: 23: 29$ & $2: 36: 17$ & $2: 32: 15$ \\
\hline Third place & $2: 55: 53$ & $*$ & $2: 36: 55$ & $2: 32: 33$ \\
\hline
\end{tabular}

By comparison, the top three athletes in the Guilin Marathon are much lower than the other events. The level of performance of the event represents the level of the event, and the lack of international competitiveness of the players' performance also leads to a significant impact on the event. In addition, if the player's score is less than the predetermined standard, the bonus will be halved, which in turn will make the player with lower grades lower the expectation of the event. If the score is not high, the bonus will not be won. The too few bonuses will affect the highlevel players to participate in such events, which makes the event in a poor circle for the invited athletes.

\section{The Level of Informationization of the Event Is Low}

In the Guilin International Marathon, the degree of using information technology is slightly inferior to those in Shanghai and Beijing. In the 2018 competition, most of the entries from participating athletes, event promotion and so on are traditional technologies, and the use of emerging technologies is relatively low. For example, in the promotion of the event, it is not possible to make good use of the emerging network from the media to promote the event in an all-round way, which greatly reduces the influence of Guilin International Marathon and ultimately leads to insufficient commercial sponsorship and other additional adverse effects.

\section{Insufficient Profitability}

The profitability of the Guilin International Marathon is an important factor limiting its expansion and development, and it is also a common deficiency of such marathons in China. Title, sponsorship, advertising, registration fees, etc. are the main sources of income, and in this source of resources, the Guilin International Marathon's title, sponsorship and advertising resources are insufficient, which is the main reason for limiting its profitability.

The title sponsor of the Guilin International Marathon is not expensive. Domestic large-scale events, such as Beijing and Shanghai International Marathon, now have a fixed title, sponsored businesses and enterprises, and the cost of the title is as high as 10 million yuan. The Guilin International Marathon is dwarfed by these several events.

\section{RESEARCH ON THE COUNTERMEASURES IN THE} DEVELOPMENT OF THE GUILIN INTERNATIONAL MARATHON

\section{A. Using the Information Platform to Promote the Event and Building the Event Brand}

Guilin International Marathon is relatively weak in the promotion of the event, which has a lot to do with the impact of the event and the lack of funds. There are similar problems in the early stage of the boutique double-standard event.

First of all, it is necessary to strengthen the depth of the cooperative media and ensure the quality of the broadcast and live media. In the official media broadcast and broadcast, strengthen the TV viewers' impression of the event and pass on the impact of the event to others. CCTV's live broadcast is the most influential. Therefore, if the Guilin International Marathon is to be more well-known in the country, CCTV's live broadcast and coverage are indispensable. The local media should also make distinctive and innovative propaganda. It is not only able to tell the local people about this matter, but also to make the promotion of the event deeply rooted in the hearts of the people.

Second, there is a need to continuously strengthen the spread of online media. With the popularity of mobile terminals and computers, network communication has become an important channel. The Guilin International Marathon should strengthen the breadth and depth of its dissemination in online media. The main channels of online media communication include event promotion, live broadcast and event reporting. In addition, it is necessary to pay attention to the use of mobile terminals that are new, highly used, and influential. For example, set up special pushes on short video platforms such as Tik Tok and Kuaishou. This kind of push cost is low, but the influence is huge, and the geographical spread is wide. Popular, headlines, clicks, comments, etc. are easy to get on the platform in a short time.

\section{B. Setting up Boutique Routes and Enriching the Event Sub-projects}

The Guilin International Marathon has been greatly improved in the design of the first three routes. However, there are many tourist attractions in Guilin, and it is difficult to have a route that covers all the tourist attractions in Guilin. Therefore, the Guilin International Marathon will work hard on the design of the track, so that the track suitable for the marathon will pass through the boutique tour route as much as possible. Also avoid excessive bending and poor road conditions.

The sub-projects of the Guilin International Marathon are divided into three categories, the full marathon, the half marathon and the Happy $10 \mathrm{~K}$. There are so many tourist attractions and tourist routes in Guilin, so there is a lot of space in the design sub-project. For example, the Yangshuo area is the best mountain sightseeing area that could be set up a scenic sightseeing tour run. People can set up a family 
[6] Li Guangying. Analysis of the status quo and development countermeasures of Lanzhou International Marathon. [J] Gansu Gaoshi Xuebao, 2017. (in Chinese) interaction, and set up a health run in the sightseeing area along the river. These resources are unique conditions for the Guilin International Marathon in Guilin's landscape and natural scenery.

\section{Rational Use of Information Technology to Make the Event Run More Efficiently}

It can be seen from the previous Guilin International Marathon events that each time there is a different degree of increase in the use of information technology than the previous one, but the use of information technology can't keep up with the replacement of information technology. Therefore, before the start of the next event, the Guilin International Marathon should pay attention to the direction of information technology in advance, and apply every link of the event to the new information technology as much as possible. In this way, the operation of the event can be more efficient, and the influence of the entire Guilin International Marathon will be further enhanced.

\section{CONCLUSION}

After three years of development, the Guilin International Marathon has greatly improved the scale and quality of the event, and it has also shown some problems. Compared with the domestic city marathon double-standard event, Guilin International Marathon has a big gap in terms of scale, quality, influence and profitability. Therefore, the Guilin International Marathon still has a long way to go. Problems in terms of hematopoietic capacity and insufficient publicity need to be continuously improved. In addition, the Guilin International Marathon also has obvious development advantages. Guilin's landscape tourism resources, good ecological environment and climate resources are the unique advantages of the Guilin International Marathon. Improving the service level of Guilin sports events, promoting the deep integration of Guilin International Marathon and other industries, and making Guilin Marathon more competitive are the aspects of Guilin International Marathon that needs to be continuously optimized.

\section{REFERENCES}

[1] Feng Wenting. Research on the Status Quo and Development Countermeasures of Dalian International Marathon. [J]. Shenyang Sports University, 2013. (in Chinese)

[2] Chen Aona, Qu Shuhua, Guo Chenggen. Analysis of the development trend of domestic marathon events. [J]. Graduate School of Beijing Sport University. Beijing Athletic University, track and field teaching and research section, 2018. (in Chinese)

[3] Yuan Lili. Analysis of the reasons for the vigorous development of marathon in recent years. [J]. School of Physical Education, Sichuan University, 2018. (in Chinese)

[4] Shi Lei, Shi Guangbin, Han Peng. The enlightenment of marathon competition organization mode on the development of university campus long-distance running. [J]. School of Physical Education, Tianjin Normal University, 2018. (in Chinese)

[5] Gao He. The status quo, problems and development strategies of Wuhan International Marathon. [J] Journal of Hubei Adult Education Institute, 2018. (in Chinese) 2018. (in Chinese)

[8] Lv Li. Social Marketing of Marathon Events. [J]. Modern Enterprise Culture (early), 2017. (in Chinese)

[9] Wu Jingting, An Yunhua, Mao Lirong. Research on landscape design (Natural Science Edition), 2018. (in Chinese)
[7] Liu Fan. Analysis of the value of the marathon. [J] Nei Jiang Ke Ji, of urban marathon track in China. [J]. Journal of Yangtze University 